University of Wollongong

Research Online

Faculty of Engineering and Information

Faculty of Engineering and Information

Sciences - Papers: Part A

Sciences

$1-1-2016$

\title{
Arc erosion behavior of La-doping titanium-zirconium-molybdenum alloy
}

Ping $\mathrm{Hu}$

Xi'An University of Architecture and Technology

Bo-Liang $\mathrm{Hu}$

Xi'An University of Architecture and Technology

Kuai-She Wang

Xi'An University of Architecture and Technology

Fan Yang

Xi'An University of Architecture and Technology

Rui Song

Xi'An University of Architecture and Technology

See next page for additional authors

Follow this and additional works at: https://ro.uow.edu.au/eispapers

Part of the Engineering Commons, and the Science and Technology Studies Commons

Research Online is the open access institutional repository for the University of Wollongong. For further information contact the UOW Library: research-pubs@uow.edu.au 


\title{
Arc erosion behavior of La-doping titanium-zirconium-molybdenum alloy
}

\begin{abstract}
La-doping titanium-zirconium-molybdenum alloys have good arc erosion resistance performances, but there is no research about the changes during the arc erosion. Arc erosion characteristics of La-doping titanium-zirconium-molybdenum alloys after 5000 operations under direct current $20 \mathrm{~V}, 15 \mathrm{~A}$ and resistive load conditions were investigated using a JF04C test system. The results indicated that the probability distribution and change trend of arc energy and arc time during 5000 operations were similar and the relationship between arc time and arc energy followed exponential function. The change of arc energy with test number was consistent to electrical resistance. Oxide particles, crater and cracks defects were discovered on the surface of La-doping titanium-zirconium-molybdenum alloy. The electrical resistance change is mainly concerned with the surface.
\end{abstract}

\section{Keywords}

erosion, molybdenum, arc, alloy, behavior, la, doping, titanium, zirconium

Disciplines

Engineering | Science and Technology Studies

\section{Publication Details}

Hu, P., Hu, B., Wang, K., Yang, F., Song, R., Yu, Z., Wang, Q., Cao, W., Liu, D., An, G., Guo, L. \& Yu, H. (2016). Arc erosion behavior of La-doping titanium-zirconium-molybdenum alloy. Journal of Alloys and Compounds, 685 465-470.

\section{Authors}

Ping Hu, Bo-Liang Hu, Kuai-She Wang, Fan Yang, Rui Song, Zhi-Tao Yu, Qiang Wang, Wei-Cheng Cao, DongXin Liu, Geng An, Lei Guo, and Hai Liang Yu 


\title{
Arc erosion behavior of La-doping titnaium-zirconium-molybdenum alloy electrical contact
}

\author{
Ping $\mathrm{Hu}^{1 *}$, Bo-liang $\mathrm{Hu}{ }^{1}$, Kuai-she Wang ${ }^{1}$, Fan Yang ${ }^{1}$, Rui Song ${ }^{1}$, Zhi-tao \\ $\mathrm{Yu}{ }^{1}$, Jiang-fei Tan ${ }^{1}$, Wei-cheng Cao ${ }^{2}$, Geng $\mathrm{An}^{2}$, Lei Guo ${ }^{3}$, Hailiang Yu ${ }^{4}$ \\ ${ }^{1}$ School of Metallurgy Engineering, Xi'an University of Architecture and \\ Technology, Xi' an 710055, China \\ 2 Jinduicheng Molybdenum Co., Ltd., Xi'an 710068, China \\ ${ }^{3}$ Ruifulai Tungsten \& Molybdenum Co., Ltd, Xi' an 721914, China \\ 4 School of Mechanical, Materials and Mechatronics Engineering, \\ University of Wollongong, NSW 2522, Australia.
}

\begin{abstract}
La-doping titnaium-zirconium-molybdenum (La-TZM) alloys have excellent performances such as high temperature strength, adequate thermal conductivity, low contact resistance and good arc erosion resistance. In this paper, the arc erosion behavior of a La-TZM alloy was studied at direct current (DC) 20V-15 A (voltage is 20 and current is 15) using a JF04C test system. Results show that the arc energy and the arc time present exponential relationship and the tendency of arc energy with test number were consistent to that of electrical resistance. Improvement of the contact pressure can effectively reduce the resistance. After the test, La-TZM was corroded with some micro-pores and micro-cracks on the surface. In addition, $\mathrm{Mo}_{4} \mathrm{O}_{11}, \mathrm{Mo}_{8} \mathrm{O}_{23}$ and $\mathrm{MoO}_{3}$ were formed on the surface, and the volatile of $\mathrm{MoO}_{3}$ resulted in the reduced weight.
\end{abstract}

Keywords: La-TZM alloy; electrical contact; arc erosion behavior

\section{Introduction}

As a kind of refractory molybdenum alloy with good high-temperature strength, creep resistance, thermal conductivity, corrosion resistance and low thermal expansion coefficient, molybdenum alloy was widely used in the electronics industry, aerospace and energy industry[1-4]. Titnaium-zirconium-molybdenum (TZM) alloy was used in electrical and electronic industry, such as cathode, grid tube high voltage rectifier devices, integrated circuits and semiconductor thin film. TZM alloy and La-Mo alloy are two most widely molybdenum alloys. When $\mathrm{Ti}$ and $\mathrm{Zr}$ are dissolved into the molybdenum substrate, they make Mo lattice distortion and form particle reinforced phase and produce the enhancement effect of molybdenum, which the mechanical properties are greatly improved at room temperature and high temperature. Thus the TZM alloy has a high melting point, high strength, high elastic modulus, low expansion coefficient, low vapor pressure, good electric conductivity, thermal conductivity, strong corrosion resistance and high temperature mechanical properties ${ }^{[5-6]}$; Rare earth doped in La-Mo alloy can improve the strength of molybdenum alloy.

Corresponding author. Tel. \& fax: +86 29 82202923. E-mail addresses: huping1985@126.com (Ping Hu). 
With development of rocket missile technology, space technology, aviation technology, nuclear power technology and other cutting-edge technology, the material requires higher working temperature (above $1500^{\circ} \mathrm{C}$ ), and has the good performance of oxidation resistance and ablation properties ${ }^{[7]}$. The refractory metal of molybdenum and molybdenum alloy have high melting point $\left(2620^{\circ} \mathrm{C}\right)$ and high temperature mechanical properties, and the density is lower than that of other refractory metals, so it favors the field of cutting-edge technology ${ }^{[8]}$. When TZM molybdenum alloy was used as cathode in electronic tube electronic, grid electrode, high-voltage rectifying element, the cathode spot temperature is extremely high due to the electron emission and ion bombardment, and it often exceeds the melting point of cathode material. Therefore, there is a serious phenomenon of cathode erosion and was damaged easily.

Qian et al ${ }^{[9]}$ studied an in-situ synthesis fabricating $\mathrm{CuW}-\mathrm{La}_{2} \mathrm{O}_{3}$ composites. The addition of $\mathrm{La}_{2} \mathrm{O}_{3}$ is useful to improve the properties of $\mathrm{CuW}$ alloys and the in situ synthesized $\mathrm{CuW}-\mathrm{La}_{2} \mathrm{O}_{3}$ composites have excellent arc erosion resistance. Many literatures reported that added trace rare earth elements will improve the comprehensive properties of silver alloys, such as Ag-Ce, Ag-Y and Ag-La ${ }^{[10-11]}$. When $0.1 \%$ to $0.5 \% \mathrm{Ce}$ was added to $\mathrm{Ag}-\mathrm{Cu}$ electrical contact materials, the corrosion resistance of arc and welding resistance ability was improved greatly.

For molybdenum and molybdenum alloy, it was easy to be oxidized in high temperature oxidation atmosphere ${ }^{[12]}$. Yang et al ${ }^{[13]}$ proved that doping La could improve the oxidation resistance of TZM alloy. However, the arc erosion of molybdenum alloy was not studied when it was applied in electronic electrical industry. In present study, $\mathrm{La}\left(\mathrm{NO}_{3}\right)_{3}$ was doped into molybdenum matrix by liquid-solid doping method, followed by the fabrication of La-TZM alloys composites by sintering. The effects of $\mathrm{La}_{2} \mathrm{O}_{3}$ addition on the microstructure, hardness, electrical conductivity, and breakdown strength were investigated.

\section{Experimental}

\subsection{Preparation of La-TZM alloy}

La-TZM alloy was produced by powder metallurgy method. The raw materials used in $\mathrm{TiH}_{2}$ powder Fibonacci particle size less than $10 \mu \mathrm{m}$, the purity of 96\%; $\mathrm{ZrH} 2$ powder particle size less than $10 \mu \mathrm{m}$, the purity of $96 \%$; $\mathrm{La}\left(\mathrm{NO}_{3}\right)_{3}$ a purity of (analytical reagent); organic carbon - stearic acid $\left(\mathrm{C}_{18} \mathrm{H}_{36} \mathrm{O}_{2}\right)$ as the carbon source, Fibonacci molybdenum powder particle size $2.0 \sim 3.5 \mu \mathrm{m}$, purity of $99.95 \%$. The chemical component is shown in Table 1.

Table 1. Design composition of the La-TZM alloy ( $\omega / \%)$

\begin{tabular}{ccccc}
\hline $\mathrm{Ti}$ & $\mathrm{Zr}$ & $\mathrm{C}_{18} \mathrm{H}_{36} \mathrm{O}_{2}$ & $\mathrm{La}\left(\mathrm{NO}_{3}\right)_{3}$ & $\mathrm{Mo}$ \\
\hline 0.5 & 0.1 & 0.25 & 1 & Bal \\
\hline
\end{tabular}


Mixing was used by solid-liquid doping method. The manufacture technology flow diagram is shown in Fig. 1. First, $\mathrm{TiH}_{2}$ and $\mathrm{ZrH}_{2}$ powders were added into pure molybdenum powder, which were mixed for $2 \mathrm{~h}$ with three-dimensional blender. After that the organic carbon stearic acid $\left(\mathrm{C}_{18} \mathrm{H}_{36} \mathrm{O}_{2}\right)$ crystals sufficiently dissolved in a suitable amount of anhydrous ethanol, then the solution was poured into the alloy powder, and sufficiently stirred so that all wet mixed, and then dried for $4 \mathrm{~h}$ in vacuum at $70^{\circ} \mathrm{C}$. Finally, the alloy powders were milled for $2 \mathrm{~h}$ at the rotational speed of $240 \mathrm{rpm}$ with molybdenum ball diameter $10 \mathrm{~mm}$ and ball feed ratio of 2:1. Compacting pressure was $150 \mathrm{MPa}$ and boost speed was $15 \mathrm{MPa} / \mathrm{min}$ holding for $1 \mathrm{~min}$. The sintering temperature is $1950^{\circ} \mathrm{C}$ for $4 \mathrm{~h}$ using segmented sintering. La-TZM alloy prepared sintered as-received plant.

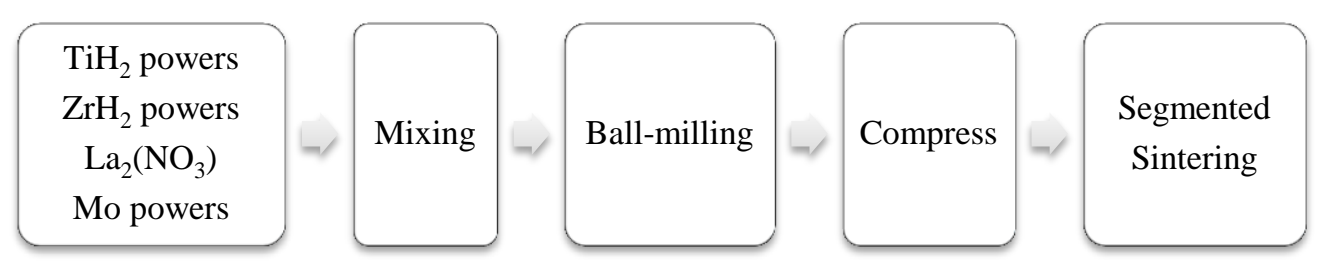

Fig. 1. La-TZM alloy sintered material preparation process flow.

\subsection{Electrical contact test}

Electrical contacts were tested by using JF04C electrical contact materials testing system with breaking measurement mode. Structural test system components are shown in Fig. 2. Test system consists of mechanical parameters of the test case, the contact resistance test cases, test cases and arc parameters bench composed of arc energy. Fusion power of this test equipment can accurately and efficiently determine arcing electrical contact material after the closure resistance and closure changes and resistance welding force parameters in pressure parameters.

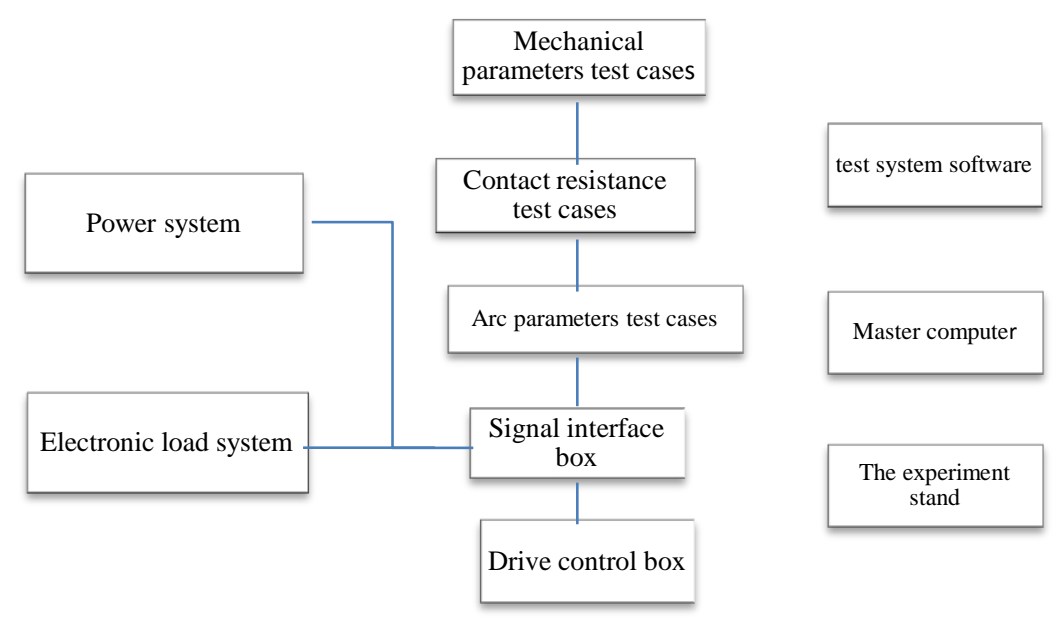

Fig. 2. Test system schematic diagram.

The experimental conditions are shown in Table 2. The size of the test sample 
was $\phi 3 \mathrm{~mm} \times 15 \mathrm{~mm}$ cylinder. The contact resistance was tested every 1000 . The test model procedure is shown in Fig. 3.

Contact is divided into the top dynamic contact and the below static contact. As shown in Fig. 3a, the beginning of contact closure. And then the contact began to separate and produced arc, as shown in Figure $3 \mathrm{~b}$, the last contact closure and arc disappeared, as shown in Figure 3c.

Table 2. Experimental parameters

\begin{tabular}{lc}
\hline Contact material & La-TZM \\
\hline Circuit condition & $20 \mathrm{~V}-15 \mathrm{~A}$ \\
Number of operations & 5000 \\
Switching mode & DC \\
Contact force, N & 10 \\
Surrounding gas & Air \\
Test interval, ms & 100 \\
Closing drive voltage, V & 2.5 \\
Turn driving voltage, V & -2.4 \\
\hline
\end{tabular}

(a)

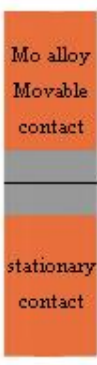

(b)

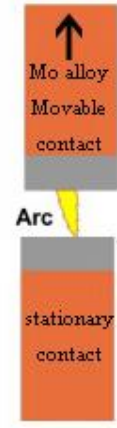

(c)

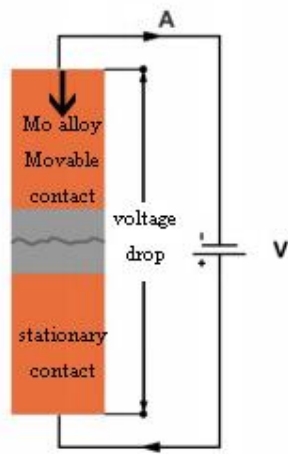

Fig. 3. Electrical contact ablation a process model: (a. contact closed, b. contact separated form electric arc, c. contact closed again)

\subsection{Characterization}

The sintering density of La-TZM alloy was measured by the displacement method. Resistivity was measured by low-voltage DC resistance tester (TH2513A, China). The hardness of La-TZM alloy sintered compact was tested with digital Vickers hardness tester (WILSON 401MVD, China). Electronic universal tensile machine (WDW300, China) was used for the tensile strength and elongation. Electrical contact material testing system was used to test arc erosion behavior under DC20V-15A in air condition (JF04C). Analytical balance (CP2245, China) was used to weigh the change quality of the sample during the test. Sample surface after arc ablation ablative case was scanned with a scanning electron microscope (SEM) JSM-6460LV and energy dispersive spectrometer (EDS) (JEOL, Japan). X-ray Diffractometer (Bruker D8 advance, Germany) was used to test the phase on the surface of the material substance formed after 
ablation.

\section{Results and discussion}

\subsection{Electrical and mechanical properties of the samples}

Electrical and mechanical properties are listed in Table. 3. The conductivity of La-TZM alloy $3.91 \mu \Omega \cdot \mathrm{cm}$. The density and Vickers hardness were increased by $1.7 \%$ and $36.3 \%$, tensile strength and elongation than the TZM alloy increased by $16.7 \%$ and $23.8 \%$.

Table 3. Properties of La-TZM alloy fabricated by powder metallurgy technology.

\begin{tabular}{|c|c|c|c|c|c|}
\hline Billet & $\begin{array}{l}\text { Electrical } \\
\text { resistivity } \\
\mu \Omega \cdot \mathrm{cm}\end{array}$ & $\begin{array}{c}\text { Density } \\
\mathrm{g} / \mathrm{cm}^{3}\end{array}$ & $\begin{array}{c}\text { Hardness } \\
\text { HV }\end{array}$ & $\begin{array}{c}\text { Elongation } \\
\%\end{array}$ & $\begin{array}{c}\text { Tensile } \\
\text { strength } \\
\mathrm{MPa}\end{array}$ \\
\hline La-TZM alloy & 3.91 & 10.07 & 210.66 & 1.54 & 342.1 \\
\hline
\end{tabular}

\subsection{Changes in tested parameter}

The arc energy, arc time closure pressure and resistance of La-TZM alloy electrical contact materials during 5000 operations are shown in Fig. 4. During the test, arc energy and arc time gradually increased before 3600 times, and then fluctuate in a larger range. The trend of closure pressure was opposite to that of the arc energy and arc time.

Contact materials arc ablation process diagram is shown in Fig. 5. At the beginning arc energy and arc time were relatively small; the ablation was from point to area with the increasing of the points. With an increasing in area, the arc time and arc energy was also increasing. As the arc erosion proceeds, the surface of molybdenum alloy began to oxidize quickly and produced volatile materials, and part of oxidize was attached to the contact surface, so it hindered the arc formation and arc time would be further reduced. With the increase of the surface oxide content, the arc energy and arc time would be reduced, and the arc energy and the amount of its oxide attached to a certain relationship. On the contrary, as the oxides volatilizing, arc energy and arc time would increase.

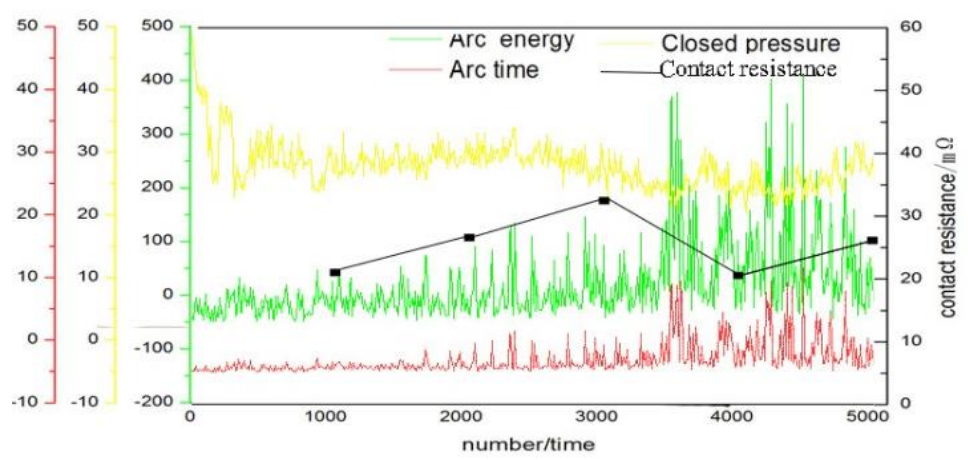

Fig. 4. Duration arc ablation tests, arc time and the energy closure pressure 
changes and the change of resistance in the process of testing.

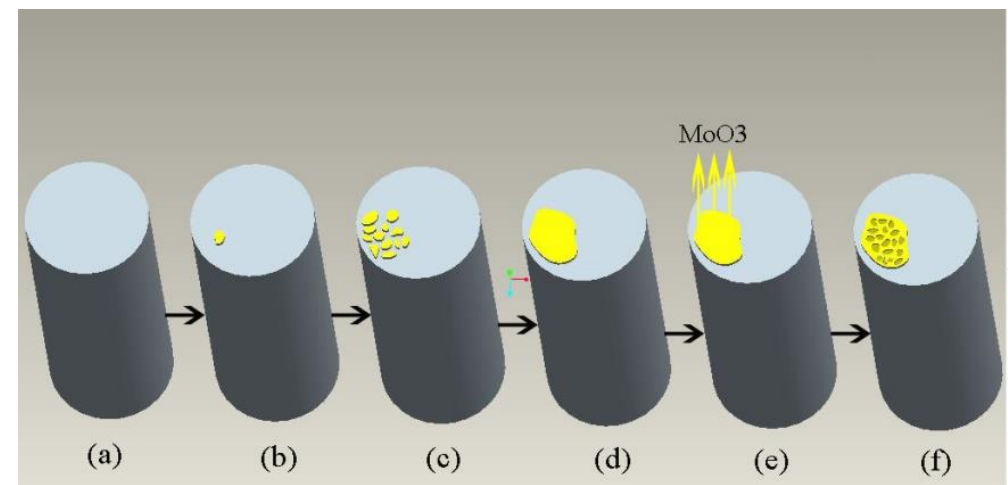

Fig. 5. Contact materials arc ablation process diagram (a. original sample, b. pitting began, c. multipoint ablation, d. regional ablation, e. $\mathrm{MoO3}$ volatilization, $f$. volatile after surface)

The resistance included the conductor material $R$ and the additional resistance $R_{\mathrm{j}}$. The additional resistance is the sum of the shrinkage resistance and the surface film resistance because of direct contact resistance between layers. No matter how careful processing of the surface of the contact, the surface was uneven with microscopic view, and they contact some small points rather than the whole area. So the actual contact area is much lower than the apparent contact area. When the current through the actual contact area, the current passed through the point of contact, and forced the current line contraction in the vicinity of these contacts. Because the effective contact area (i.e., the actual contact area) is less than the apparent contact area, the result additional resistance is called shrinkage resistance. Due to various reasons, the contact surface was covered with a layer of film conductivity, which was very poor such as metal oxides, sulfides made electrical conductivity very poor, which was called the surface film resistance.

Contact resistance is related to the contact material, contact stress, contact forms, surface and clean condition. Because the surface film resistance is difficult to calculate, the available empirical formula (1) can be used to evaluate the contact resistance as follows:

$$
R_{\mathrm{j}}=\frac{K}{F m}
$$

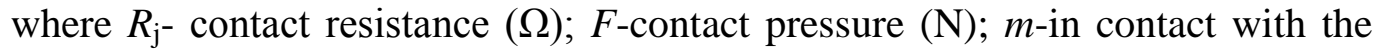
contact form related to a constant point contact for $m=0.5$, line contact $m=0.5$ $\sim 0.7$, surface contact $m=1$; and $K$ - contact material, the contact surface processing methods, related to the situation in constant contact surface. The closure pressure corresponded to the changes in the testing process.

As shown in Fig. 4, the contact resistances are $20.43 \mathrm{~m} \Omega, 26.31 \mathrm{~m} \Omega, 32.52$ $\mathrm{m} \Omega, 19.99 \mathrm{~m} \Omega$ and $25.85 \mathrm{~m} \Omega$. The variable of contact resistance with times divided into three parts. The first part increased with the times before 3000 times. The second part decreased with times between 3000 and 4000 times. And the third part increased with the times between 4000 and 5000 times. During the 
ablation process, the change of resistance reflects the way of contact and the amount of oxide production, and the early stage of the surface contact area is more and more large, the oxidation is also more and more serious. The increasing in arc energy and arc time of the electric contact enable caused severe oxidation of surface, and then the contact resistance increased. On the contrary, when the arc energy and arc time reduced, the resistance reduced. The change of arc energy and arc time was consistent with the change of the resistance.

\subsection{Distribution and relationship of arc time/arc energy}

Fig. 6 shows the arc energy and arc time of the distribution and relationship curve La-TZM alloy 5000 exposure experiment. In Fig. 6, there is a certain quantitative relation between arc time and arc energy. The arc energy is relatively larger than $300 \mathrm{~mJ}$ when arc time more than $12 \mathrm{~ms}$, but only a fewer of points, so a high arc energy in the test could not last a long time. Arc energy is mainly distributed in the arcing time of 1 9 ms, and the longest and shortest of arc time when the arc burning area where energy is relatively small when the arc time in 4-9 ms, the arc energy is located bigger. Arc energy and arc time and welding power distribution are not the same. The $95 \%$ of welding force is less than $37 \mathrm{~g}$ in 5000 test, and the average arc energy, arc time and welding forces are $30 \mathrm{~mJ}, 1$ $\mathrm{ms}$ and $15 \mathrm{~g}$, respectively.

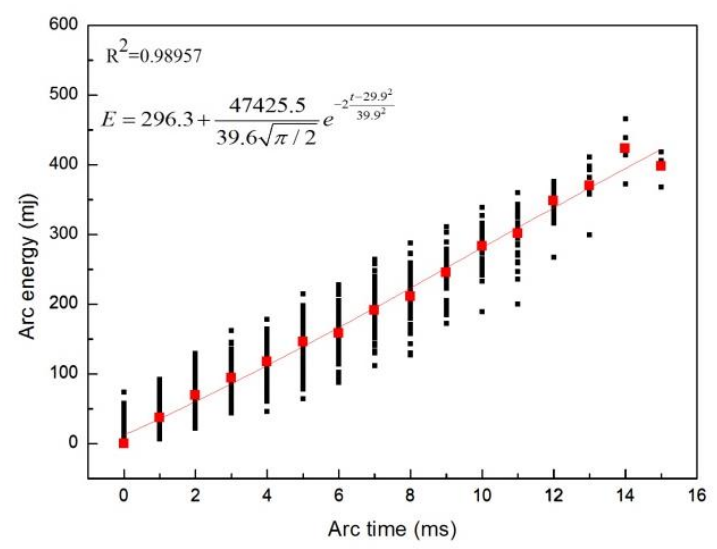

Fig. 6. The distribution of arc time and arc energy and the relationship between the arc time and arc energy.

The results in Fig. 6 indicate that arc time has an influence on arc energy, but arc time has no direct influence on welding force. Kubo et al found that the relationship between arc time and arc energy can be described with the following equation [24]:

$$
E=\sum U \cdot I \cdot t
$$

where $E$ is arc energy, $U$ is arc voltage, $I$ is arc current and $t$ is arc time. The relationship between arc erosion (mass loss) and arc energy can be described with the following equation [24]:

$$
W=c \cdot E^{d}
$$

where $W$ is arc erosion, $c$ and $d$ are constants related to material. Wang 
established the relationship between arc erosion and arc time according to experiment result [25]. The relationship between arc erosion and arc current can be expressed by the following equation:

$$
W=k \cdot I \cdot t
$$

where $k$ is coefficient related to material. According to Eqs. (3) and (4), we can get the following equation:

$$
E=a \cdot I \cdot t
$$

where $a$ is coefficient related to material.

The previous studies have shown that arc energy and arc time have an important influence for arc erosion of material, and arc time also has an important influence for arc energy. In this paper, the relationship between arc time and arc energy of La-TZM alloy electrical contact material under DC20V-15A and resistive load conditions during 5000 operations was discussed. The relationship curves between arc energy and arc time were clearly represented in Fig. 4, where the relationship between $\operatorname{arc}$ energy $(E)$ and arc time $(t)$ is well expressed by an exponential law, so we can get the following equation by data fitting:

$$
E=296.3+\frac{47425.5}{39.6 \sqrt{\pi / 2}} e^{-2 \frac{t-29.9^{2}}{39.9^{2}}}
$$

The correlation of data fitting $\left(R^{2}\right)$ on Eq. (6) is 0.98957 , which indicates that the relationship between arc energy and arc time of La-TZM alloy electrical contact materials in this experimental conditions can be described used by Eq. (6). As a result, arc energy is exponentially increases with the arc time increasing in this experiment.

\subsection{Mass loss and surface products}

By measuring the mass loss of a static contact and moving contact, the total mass was $1.5027 \mathrm{~g}$ before experiment and $1.4999 \mathrm{~g}$ after test. The mass loss was $0.0028 \mathrm{~g}$, which was accounted for $0.18 \%$ of the original sample mass, and the loss of the static contact surface is larger than of the moving contact. Fig. 7a represented corrosion on the surface of the moving contact area and corrosion products significantly less than the static contact in Fig. 7b. The two contact surfaces were part of the corrosion, and others was normal. 


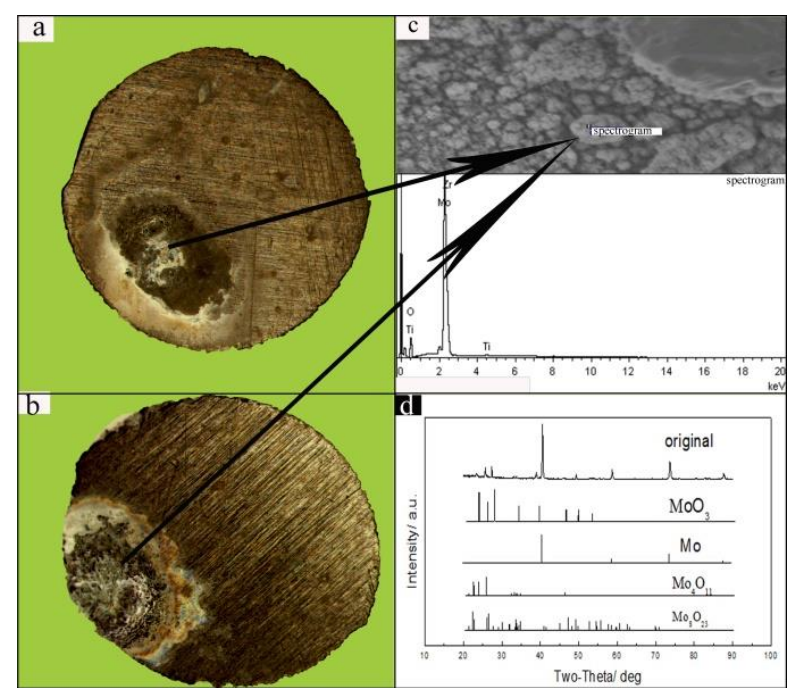

Fig.7. Contact voltage 20v- current $15 \mathrm{~A}$ ablation panorama (a. moving contact, b. static contact, c. EDS analysis, d. XRD phase analysis )

As shown in Fig. 7c, we find that the surface element was mainly oxygen and molybdenum. That was to see the surface products was mainly oxide molybdenum.

Fig. $7 \mathrm{~d}$ shows the phase of the samples after corrosion test. From the phase analysis result, the products on the surface of the arc ablation the La-TZM alloy are mainly $\mathrm{MoO}_{3}, \mathrm{Mo}_{8} \mathrm{O}_{23}$ and $\mathrm{Mo}_{4} \mathrm{O}_{11}$ in ablation experiment tests which born in $\mathrm{MoO}_{3}$ reduction process, so it would appear $\mathrm{Mo}_{8} \mathrm{O}_{23}$ and $\mathrm{Mo}_{4} \mathrm{O}_{11}$ between the $\mathrm{MoO}_{2}$ and $\mathrm{MoO}_{3}$ when the La-TZM alloy was oxidized.

Molybdenum is stable in the air or water when the temperature was not too high. When Molybdenum was heating in air, the color started from white (color) to dark gray; when the temperature was up to $600^{\circ} \mathrm{C}$, the molybdenum started by slow oxidation, and generated yellow product $\left(\mathrm{MoO}_{3}\right.$ becomes white at room temperature). At the start of the arc ablation temperature belows $600{ }^{\circ} \mathrm{C}$, molybdenum firstly forms $\mathrm{MoO}_{2}$, and then forms $\mathrm{Mo}_{8} \mathrm{O}_{23}$ and $\mathrm{Mo}_{4} \mathrm{O}_{11}$ with the $\mathrm{MoO}_{2}$ further oxidized. As the temperature rose to above $600{ }^{\circ} \mathrm{C}$, the intermediate was oxidized into $\mathrm{MoO}_{3}$ quickly. But the $\mathrm{MoO}_{3}$ on the surface would evaporate, and there will be a part of the $\mathrm{MoO}_{3}$ product reserved on the surface. When the electric arc was formed rapidly in the process, the surface was heated and cooled rapidly, so only a part of the $\mathrm{MoO}_{3}$ was volatilized, and the rest of the products were cooled on the surface. The white product was formed at room temperature in Fig. $7 \mathrm{a}$ and $7 \mathrm{~b}$.

\subsection{Surface morphology analysis}

As shown in Fig. 8, La-TZM alloy specimen surface mainly forms the following three defects in the ablation process under the condition of DC20 V-15A: ablation oxide particles, holes and cracks. One of the most serious defects is crack and it forms in the static contact surface, it will be destructive damage to the contact material.

Firstly, the surface area forms oxide particlesunder the arc pitting ablation. 
With the increase of arc time and arc energy, surface ablation would aggravate, which would be from the oxidation corrosion area spread to the no oxidation area, and it would make the surface ablation area and no ablation area to form small "steps". It has formed the $\mathrm{MoO}_{3}$ oxidation particles in Fig. 8a. The oxidation spread to other areas and began to form porous layer structure, so the ablation process had a certain direction, the residual $\mathrm{MoO}_{3}$ on the surface particles was solidified into pellets due to a sharp change of temperature in the process of ablation led to its failure to synthesize surface. As shown in Fig. 8a, the particles on the surface of oxidized was further enlarged, we could see the oxide particles and sintering structure on the surface. At the high temperature, it could make the sinter state to form on thesurface under air atmosphere, and became sintering structure in Fig. 10b, which further shows that the temperature was higher in the process of arc ablation.

As oxidation continues and arc energy increases, ablation started from the surface to the inside of sample. When the loose structure was partial oxidation, the surface oxide would evaporate, and the larger arc made the oxidation longitudinal, so the internal temperature of the sample increased rapidly, the volatiles from the sample internal causes and volatile inside of sample, the defects of holes in Fig. 8c. the holes was small and deep, but it only a little on the surface after ablation.

The rapid solidification of melted layer leads to the increasing of vacancy and dislocation density in melted layer microstructure. Increase of vacancy and dislocation density will decrease grain boundary intensity, which increases the possibility of grain boundary crack formation under stress action ${ }^{[14]}$. As shown in Fig. 8d, not only on the specimen surface melting state of matter, but also there were a little of cracks. But the cracks was tiny, so La - TZM alloy had good erosion resistance as the electric contact materials.
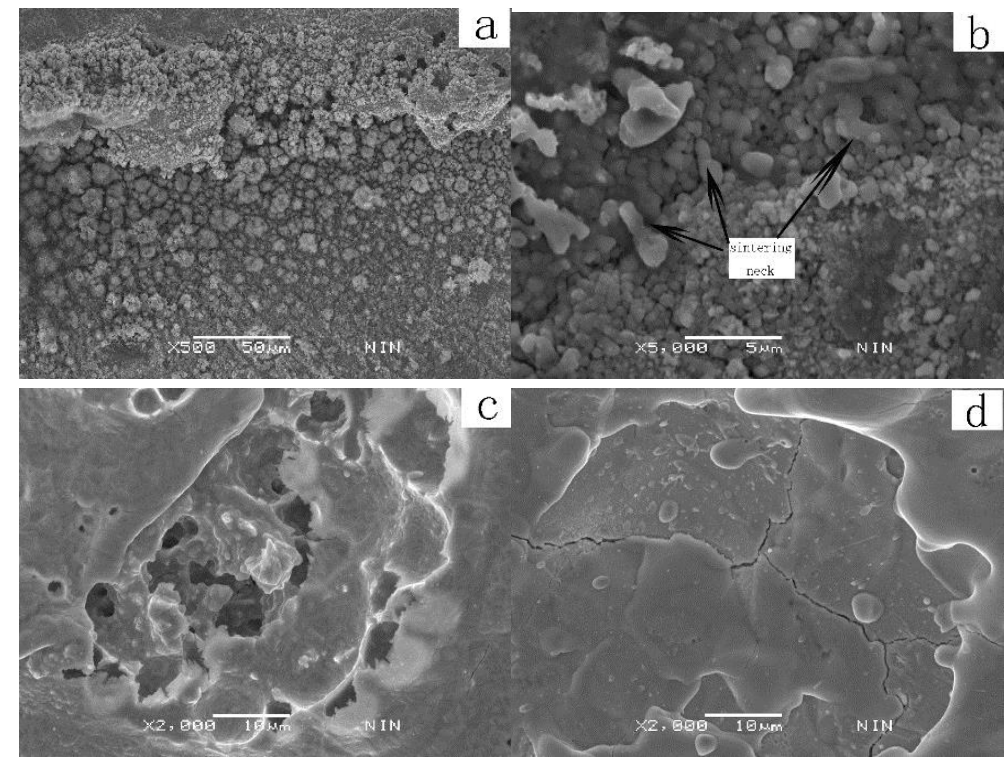

Fig. 8. Contact surface ablation SEM photos.

\section{Conclusions}


(1)The change and distribution of arc energy and arc time are similar and the relationship between them can be expressed using by the followed exponential function: $\quad E=296.3+\frac{47425.5}{39.6 \sqrt{\pi / 2}} e^{-2 \frac{t-29.9^{2}}{39.9^{2}}}$. Experimental tests correlation coefficient $\left(R^{2}\right)$ is 0.98957 .

(2)The mass loss of product is mainly volatile $\mathrm{MoO}_{3}$ which is formed during the arc ablation. Arc erosion amount of La-TZM alloy increases with arc energy. Arc energy and arc time has the opposite trend to the electrical resistance.

(3) The surface of La-TZM alloy mainly forms oxide particles, defects and cracks crater defects. The resistance change is mainly concerned with the surface.

\section{Acknowledgments}

This work is financial supported by the Science and Technology Coordinating Innovative Engineering Project of the Shaanxi province(2014KTCQ01-35), the third Science and Technology Innovation Fund Project of the Western Metal Materials Co., Ltd(XBCL-3-21), the Technology transfer projects in Colleges and Universities of Xi'an science and technology plan(CXY1521(3)), and the Science and technology Foundation of Xi'an University of Architecture and Technology(QN1505).

\section{References}

[1] Fan Jinglian, Cheng Huichao, Lu Mingyuan, Huang Boyun, Tian Jiamin. (2008). Effect of Alloyed Elements Ti, Zr on the Property and Microstructure of Mo Alloy. Rare Metal Materials and Engineering, 37(8): 1471-1474.

[2] Mrotzek T. , Hoffmann A., Martin U. Hardening mechanisms and recrystallization behaviour of several molybdenum alloys. Refractory Metals \& Hard Metals, 2006, 24(4):298-305.

[3] Kopp.R. Seeking economies in Sintering in Molybdenum. Metal Poder Report.2002, 57 (10): 46-52.

[4] Cockeram B V. The mechanical properties and fracture mechanisms of wrought low carbon arc cast (LCAC), molybdenum-0.5pct titanium-0.1pct zirconium (TZM), and oxide dispersion strengthened (ODS) molybdenum flat products. Materials Science \& Engineering A, 2006, 418(s 1-2):120-136.

[5]Mrotzek T, Hoffmann A, Martin U. Hardening mechanisms and recrystallization behaviour of several molybdenum alloys. International Journal of Refractory Metals \& Hard Materials, 2006, 24(4):298-305.

[6] Kopp.R. Seeking economies in Sintering in Molybdenum. Metal Poder Report.2002, 57 (10): 46-52.

[7]Squire T H, Marschall J. Material property requirements for analysis and design of UHTC components in hypersonic applications. Journal of the European Ceramic Society, 2010, 1:11:11-13. 
[8]Cockeram B V. The mechanical properties and fracture mechanisms of wrought low carbon arc cast (LCAC), molybdenum-0.5pct titanium-0.1pct zirconium (TZM), and oxide dispersion strengthened (ODS) molybdenum flat products. Materials Science \& Engineering A, 2006, 418(s 1-2):120-136.

[9]Qian K, Liang S, Peng X, et al. In situ synthesis and electrical properties of $\mathrm{CuW}-\mathrm{La} 2 \mathrm{O} 3$ composites. International Journal of Refractory Metals \& Hard Materials, 2012, 31(3):147-151.

[10] Hetzmannseder E, Rieder W F. Make and break erosion of $\mathrm{Ag} / \mathrm{MeO}$ contact materials[J]. IEEE Trans on CPMT:Part A, 1996, 19(3): 397-403.

[11] Lee G G, Toshiyuki O, Koji H, et al. Synthesis of $\mathrm{SnO} 2$ particle dispersed $\mathrm{Ag}$ alloy by mechanical alloying.Journal of the Japan Society of Powder and Powder Metallurgy, 1996, 43(6): 795-797.

[12]Peng D Q, Bai X D, Zhou Q G, et al. The oxidation behaviour of molybdenum ion-implanted zircalloy-4 in air at $600^{\circ} \mathrm{C}$. Vacuum, 2004, 75(2):121-131.

[13]Yang F, Wang K S, Hu P, et al. La doping effect on TZM alloy oxidation behavior. J. Alloy. Compd. 593(2014) 196-201.

[14]Wu C, Yi D, Weng W, et al. Arc erosion behavior of Ag/Ni electrical contact materials. Materials \& Design, 2015, 85:511-519. 